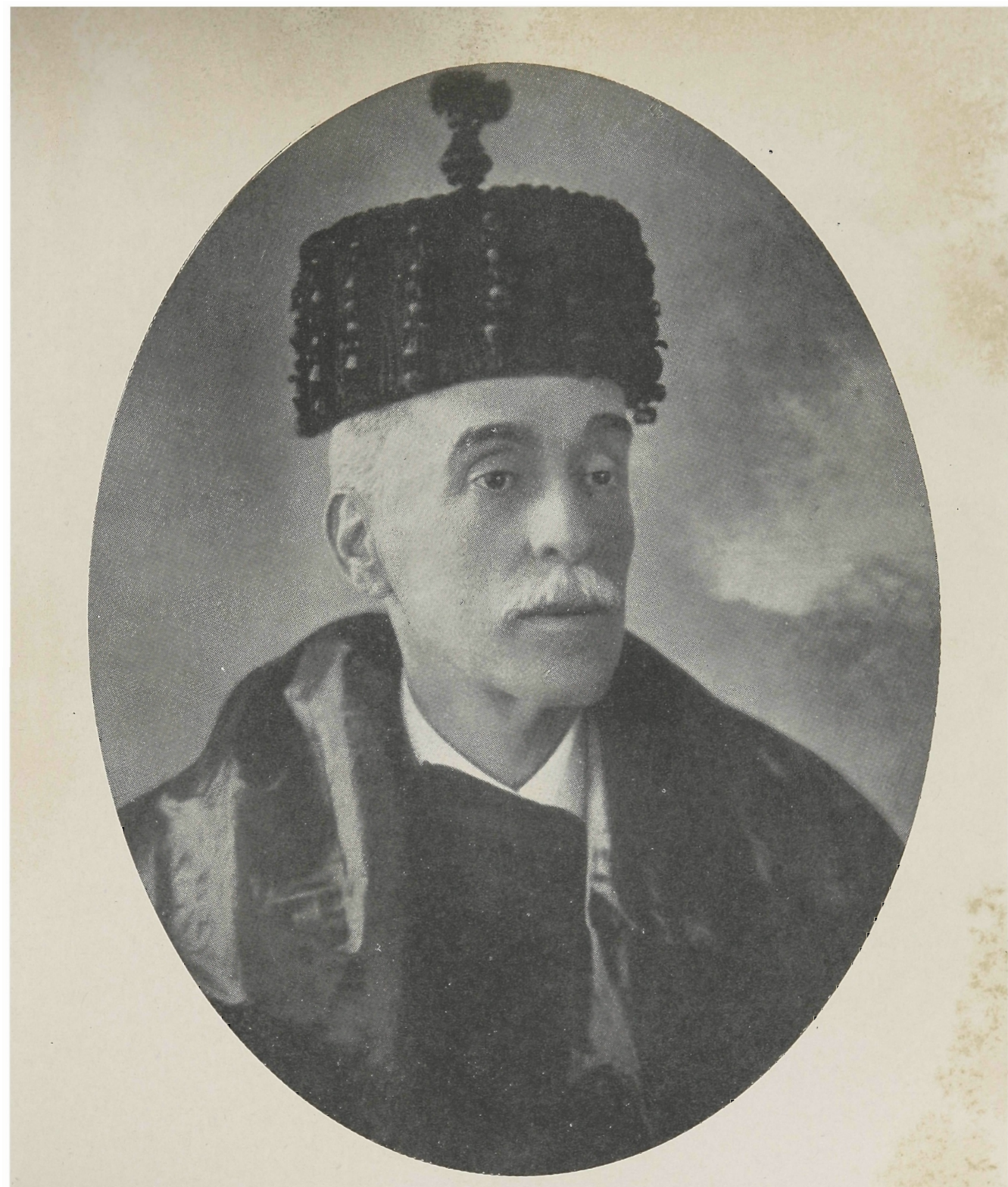

Professor Dr. Candido Nazianzeno Nogueira da Mota 


\section{Professor Dr. Candido Motta}

A Faculdade de Direito de S. Paulo perdeu um mestre ilustre e querido. A 16 de março de 1942, nesta capital, faleceu o professor Candido Nazianzeno Nogueira da Motta.

Filho do velho educador Fernando Maria Nogueira da Motta e de d. Mariana Francisca da Motta, o professor Candido Motra nasceu em Porto Feliz, neste Estado. Iniciou os seus estudos de humanidades em Capivari, com seu pai. Feitos os preparatórios, matriculou-se na Faculdade de Direito de S. Paulo, em 1888, recebendo o gráu de bacharel em 3 de novembro de 1891. Nomeado promotor público de Amparo, foi transferido para a segunda promotoria pública da comarca da capital. Em 1896, foi delegado de polícia, sendo chefe de polícia o dr. José Xavier de Toledo, mais tarde presidente do Tribunal de Justiça do Estado. Exonerou-se para inscrever-se em concurso, na Faculdade de Direito, para a vaga aberta com a morte do dr. Severino Prestes. Aprovado, foi nomeado lente substituto por decreto de 19 de agosto de 1897 e catedrático por decreto de 21 de maio de 1908.

Em 1898 foi eleito deputado estadual, tendo sido um dos membros da chamada dissidência paulista. Militou no jornalismo. Representou o Brasil, em 1908, no Congresso Científico Pan-americano, reunido em Santiago do Chile, quando apresentou a tese "Menores delinquentes e o seu tratamento no Estado de São Paulo", que teve larga repercussão e renome.

Em 1909, foi deputado federal por S. Paulo e, em 1916, secretário da Agricultura, Indústria, Comércio e Obras Públicas, na presidência Altino Arantes. Foi eleito senador estadual em 1922, e, reeleito, exerceu funções até o ano de 1930. 
Constituiu uma estréia auspiciosa a sua tese de concurso, o trabalho intitulado "Classificação dos criminosos". Era um escrito revolucionário, no Brasil. Ainda mal e indistintamente, em nosso país, se percebiam os ecos do movimento renovador da ciência criminal, desencadeado no terceiro quartel do século dezenove por Lombroso, seguido mais tarde por Ferri e Garofalo. O jovem bacharel brasileiro, em 1897, contando apenas 27 anos, ainda no início da sua carreira, já se mostrava senhor de amplos conhecimentos acerca das novas idéias, fadadas a operar profundas modificações no sistema repressivo de todos os países. E a sua orientação iria exercer decisiva influência no direito penal brasileiro, através dos ensinamentos que ministraria, daí em diante, da sua cátedra.

Para essa realidade inegavel, que foi a florescência do pensamento criminológico como efeito da sua difusão pelo professor paulista, muito concorreu o largo prestígio de que, logo ao ser publicado, se redourou aquele livro inicial. O mundo científico europeu conheceu-o e louvou-o. "A mais perfeita obra sobre o assunto", qualificou-o Lombroso. ENRico Ferri fez-lhe elogiosas citações, em sua "Sociologia Criminal" Angiolını, realçando a repercussão que na América haviam tido as afirmações da escola positiva do direito penal, a julgar do livro do professor Candido MotTa, considerava o jovem mestre como um dos escritores estrangeiros que se revelavam "mais conhecedores da nova escola". Escrevendo na "Pevue Pénitenciaire", em 1898, Henry Prudномме sentenciava: "Este trabalho denota no autor um conhecimento aprofundado da questão e das obras de numerosos autores que, antes dele, abordaram esse estudo. Dá uma alta idéia do nivel dos estudos em S. Paulo".

Numa época em que, no Brasil, o campo do direito penal não transcendia aos limitados horizontes que as construções clássicas haviam atingido, a posição combativa assumida pelo professor CANDIDo MotTA representava uma vanguarda quasi aventurosa, a demonstrar o seu espírito progressista e o destemor com que se colocava, isento de preconceitos, a serviço da ciência e da justiça. 
O professor Reynaldo Porchat, discursando na festa comemorativa do centenário dos cursos jurídicos no Brasil, nesta Faculdade, a 11 de agosto de 1927, empreendeu meticulosa análise do "pensamento filosófico no primeiro século da Academia". E, num capítulo, estudando as concepções do direito penal contemporâneo, a mudança verificada nos métodos de estudo da matéria, a apaixonada luta entre as correntes extremas, e evocando a fé com que, na vitória da sua causa, haviam surgido os novos expositores, aos quais, a seu ver, se devia conferir a palma da vitória, salientou o papel memoravel desempenhado pelo professor Candido Motтa nessa peleja espiritual, no setor brasileiro: "E $\mathrm{E}$ de justiça registar, desde que estou delineando o influxo filosófico no pensamento jurídico desta Academia - declarou o orador - que quem teve primeiro, na cadeira de direito criminal, a coragem de trazer para os novos estudos os tesouros colhidos pela nova ciência que cintilou principalmente na Itália, foi o meu estimado colega de ano, o douto professor Candido MotTa, que ainda hoje mantem, convencido, a mesma orientação na cátedra conquistada com a defesa da tese, que escreveu, sobre a classificação dos delinquentes segundo a escola positiva".

As palavras comovidas com que assinalamos, na "Revista" da Faculdade, o desaparecimento do inolvidavel professor, não são apropriadas, nem suficientes, para rememorar a sua produção científica. Desse relato, a largos traços, já se incumbiu a própria Congregação, designando o professor NoÉ Azevedo para proferir nesta Casa, na sessão comemorativa do falecimento do professor Candido MotTa realizada a 16 de abril, a conferência que estampamos noutra parte deste numero.

$\mathrm{Na}$ apreciação realizada pelo professor NoÉ Azevedo, observa-se a fidelidade inalteravel com que o mestre falecido sempre honrou os princípios hauridos na mocidade, utilizando-os como uma bússola inseparavel dos seus trabalhos ulteriores, muitos dos quais vieram a lume nestas mesmas páginas em que, agora, com infinito pesar, lamentamos o seu trespasse. 
Esse é, na verdade, o exclusivo propósito destas linhas. 0 de cristalizar num escrito a mágua que penetra o coração de todos, na Faculdade, ante a perda do saudoso mestre. Aliava ele a brilhantes qualidades de espírito um coração boníssimo. Aí está a razão pela qual se tornavam seus amigos e devotados admiradores todos quantos o conheciam e, em especial, todos quantos, como seus alunos, ouviram as suas preleções, sempre repassadas daquele comunicativo entusiasmo peculiar aos apóstolos das grandes reformas.

Tendo-se aposentado em 1937, o preclaro mestre nunca se afastou inteiramente desta Casa, à qual se mantinha ligado pelos laços afetivos. Visivel era a emoção que lhe causava a passagem ao repouso, a que fazia jús após as canseiras de uma vida consagrada ao ensino, a S. Paulo e ao Brasil. Teve então oportunidade de enviar à Faculdade de Direito uma carta, em que recorda o que haviam sido os quarenta anos empregados na bela tarefa de educador da mocidade. Durante esse longo lapso de tempo, não haviam sido poucos os dissabores sofridos, confessou à despedida, com laivos de amargura. Confortavam-no, porém, a estima e o respeito de que era cercado pela juventude e pelos professores, alguns dos quais haviam sido seus discípulos.

Com a mesma estima e o mesmo respeito todos se curvam, neste momento, ante o seu vulto inapagavel, reverenciando a memória do professor Candido Motta.

Obras do professor Candido MotTa, existentes na Biblioteca da Faculdade de Direito:

I - "Justiça Criminal - Relatório apresentado ao Procurador Geral do Estado", São Paulo, 1895, 1 volume;

II - "Classificação de criminosos", (disertação de concurso), São Paulo, 1897, 1 volume;

III - "Discursos pronunciados nas sessões legislativas de 15 de junho e 30 de agosto de 1898 , sobre o projeto que altera 
algumas disposições da organização judiciária do Estado", São Paulo, 1898, 1 volume;

IV - "Discurso proferido, como secretário da Agricultura, por ocasião da entrega da Bandeira ao Regimento de Cavalaria da Força Pública", São Paulo, s. d., 1 volume;

V - "Muro divisório entre terrenos", São Paulo, 1899, 1 folheto;

VI - "Interdição de d. Maria Isabel Jardim", (alegações forenses), São Paulo, 1905, 1 folheto;

VII - “Os menores delinquentes e o seu tratamento no Estado de São Paulo", São Paulo, 1909, 1 volume;

VIII - "Classificação dos criminosos - Introdução ao estudo do direito penal”, São Paulo, 1925, 1 volume;

IX - "Agora e sempre pela República parlamentar", São Paulo, 1933, 1 volume;

X - "São Paulo e a República - Ainda a grande obra de José de Anchieta", São Paulo, 1935, 1 volume;

XI - "Nova tormenta", São Paulo, 1939, 1 volume. 